\title{
A CONCEPT OF A POWER ELECTRONIC CONVERTER FOR A BLDC MOTOR DRIVE SYSTEM IN AVIATION
}

\author{
Dariusz SOBCZYNSKI \\ Rzeszow University of Technology, 12 Al. Powstancow Warszawy, PL-35-959 Rzeszow, Poland \\ E-mail:dsobczyn@prz.edu.pl
}

Received 27 January 2014; accepted 20 January 2015

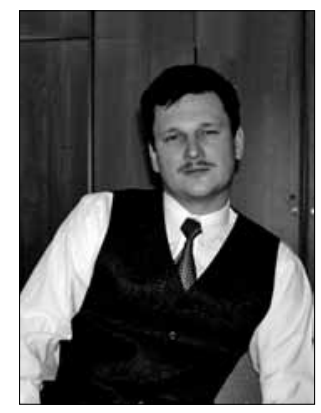

Dariusz SOBCZYNSKI, PhD Eng.

Education: MSc and PhD degrees from Rzeszow University of Technology, Poland, in 1996 and 2004, respectively.

Affiliations and functions: assistant and senior lecturer at the Faculty of Electrical and Computer Engineering of Rzeszow University of Technology, Department of Power

Electronics and Power Engineering.

Research interests: high-speed induction motor drives, especially power electronic converters for high-speed drives.

Publications: author and co-author of over 30 scientific and technical papers.

\begin{abstract}
Realisation of a high-speed drive using a BLDC motor, especially that of low and medium power and with rotational speed of up to $40000 \mathrm{rpm}$ designed for use in aviation appliances, became possible due to rapid progress in electronic power control technology. An increase of both capability and diversity of electronic power circuits results from the increase of semiconductor element voltage and current operational ranges simultaneously with the improvement of their dynamical parameters, as well as from application of up-to-date microprocessor and programmable circuits for control purposes. Choice of topology for a drive system to be used in aviation appliances, including the electronic power converter, is based on the following quality and economy-related criteria: single-phase supply and sinusoidal waveform of power network current; high efficiency and reliability; small overall dimensions; minimum number of semiconductor elements; and low price. Various technical solutions are possible here, concerning both the scope of the power circuit and the control system.
\end{abstract}

Keywords: aircraft, brushless DC motor, permanent magnet motor, power electronic converters.

\section{Introduction}

To efficiently use electricity, increase the range and reduce the weight of an aircraft, a high efficiency and low weight drive system has to be used to drive the propeller. Hybrid systems use both an electric motor and an internal gasoline engine. The tasks of the motors are different, for example, the plane hovers and flies due to the energy obtained from the batteries, but it also has an onboard gasoline engine as an additional, secondary drive (or vice versa: the electric drive may function as a supporting drive). In the paper, the use of highspeed motors supplied through electronic power converters is proposed. Recently, small high speed brushless DC (BLDC) motors have become very popular in many application areas (Jurecka, Bencalik 2012; Gapiński, Stefański 2014; Kaddour 2014; Jurković, Žarko 2012). BLDC motors consist of a permanent magnet rotor with a three-phase stator winding. Such solutions do not use brushes for commutation; instead, they are electronically commutated. Since it has no mechanical commutator, the BLDC motor is more reliable than a conventional DC motor. A BLDC motor drive would result in the reduction of the mass of the whole drive system, also BLDC motors offer longer life and require less maintenance than conventional brushed DC motors. In addition, the ratio of torque delivered to the size of the motor is higher, making them useful in applications where space and weight are critical factors. The speed and torque of the motor depend on the strength of the magnetic field generated by the energized windings of the motor, which depend on the current through them. Therefore, an adjustment of the rotor current would change the motor's speed (Sanita, Kuncheria 2013; Bo et al. 2010). 


\section{Converter design for a BLDC motor}

The choice of topology for a drive system including an electronic power converter is based on quality and economy related criteria (Rajashekara, Akin 2013). A BLDC motor is driven by voltage strokes coupled with a given rotor position. These voltage strokes must be applied properly to the active phases of the three-phase winding system so that the angle between the stator flux and the rotor flux is kept close to $90^{\circ}$ to obtain maximum generated torque. By simply varying the voltage across the motor, one can control the speed of the motor. When using PWM outputs to control the six switches of the three-phase bridge, it is easy to achieve the variation of the motor voltage by changing the duty cycle of the PWM signal (Binkowski et al. 2011).

The drive system consists of a three-phase inverter, a BLDC permanent magnet motor, and a DC power supply (Binkowski 2011).

The whole control system shown in Figure 1 has been implemented in an FPGA Cyclon II. The applied system has 8256 logic elements. For the program support of the FPGA software package, Quartus was used. Figure 2 shows a block diagram of the current and voltage control system realized in Quartus.

When a motor works in the catwalk state its speed is controlled, and, in the case of short-term power blackouts, the drive's control and adjustment remain active.

There are two ways to control the phase-currents of a BLDC: firstly, through the measurement of the phase currents, which are compared and forced to follow a quasi-square template; secondly, through the measurement of the DC link current, which is used to get the magnitude of the phase-currents. In the first case, the control is complicated, because three quasi-square current templates shifted 120 for the three phases have to be generated. The measured currents are sensed through current sensors and converted to voltage signals. These signals are then rectified, and a DC component with a value of the ceiling of the currents is obtained, as shown in Figure 1. This DC signal is compared with a desired reference, and from this comparison an error signal is obtained. This error is then passed through a PI control to generate the PWM for all the six transistors of the inverter, which are sequentially activated by the shaft position sensor. The control strategy also allows regenerative breaking. When the brake signal is applied, the stator field is reversed by 180 electric degrees (Fig. 2). This action produces an instantaneous change in the direction of torque, causing fast decrease of the speed of the machine, which begins to return its energy to the DC link (Luongo et al. 2011; Sobczyński 2009).

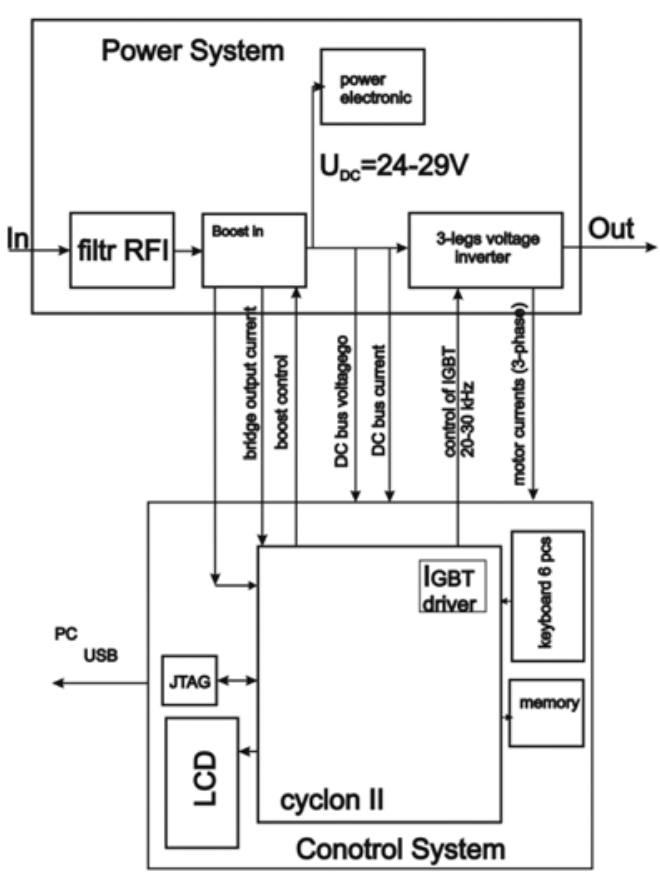

Fig. 1. Block diagram of the BLDC converter

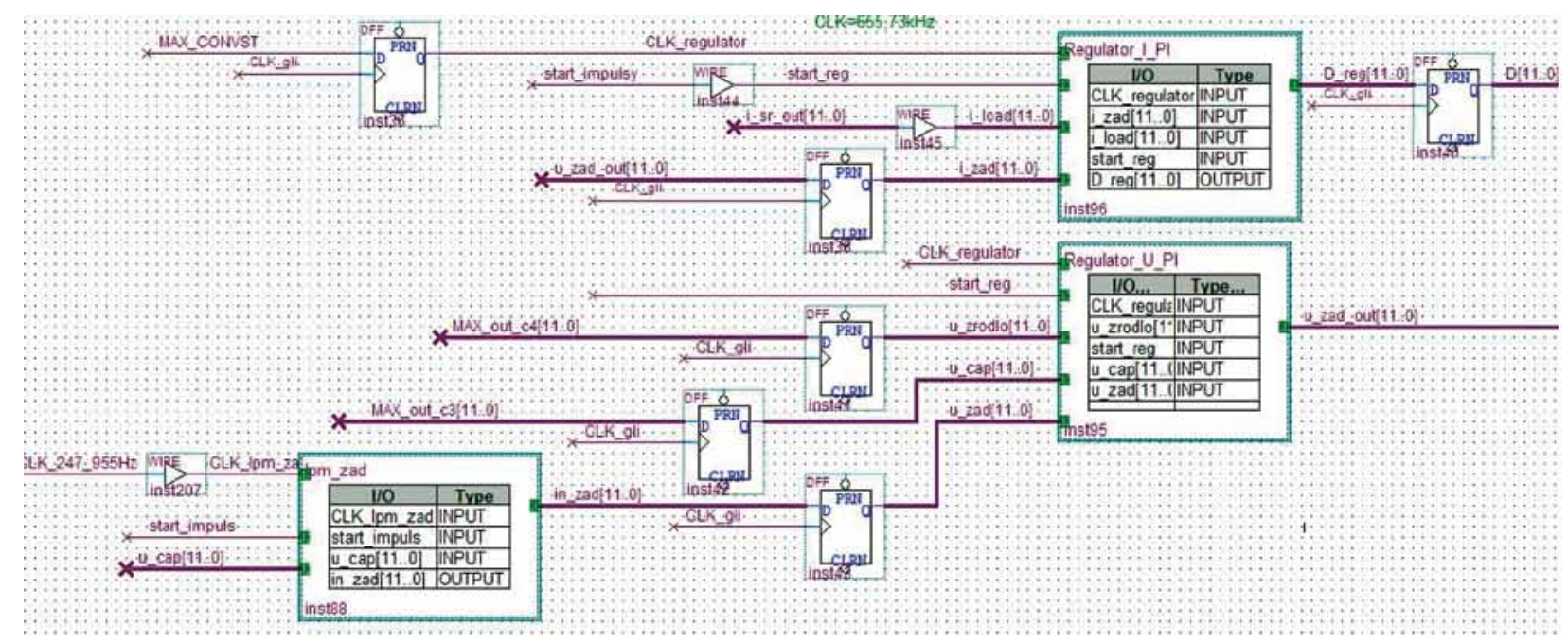

Fig. 2. Diagram of the implemented control system 


\section{Results}

The proposed method of control is implemented using a BLDC motor of supply voltage of 24-30 V. The three phase inverter is constructed using IGBT switches (Fig. 3). The gating signal required for these switches is given through the rotor position sensor. The controller turns off and on the voltage supplied by the batteries as pulses, typically at $8 \mathrm{kHz}$. The inductance in the system acts like a damper; therefore, the motor actually gets a very smoothed-out current supply with a trivial $8-\mathrm{kHz}$ ripple. The ripples are so small in proportion to the average voltage, and the inertia in the system is so high that the motor runs at a virtually constant speed.
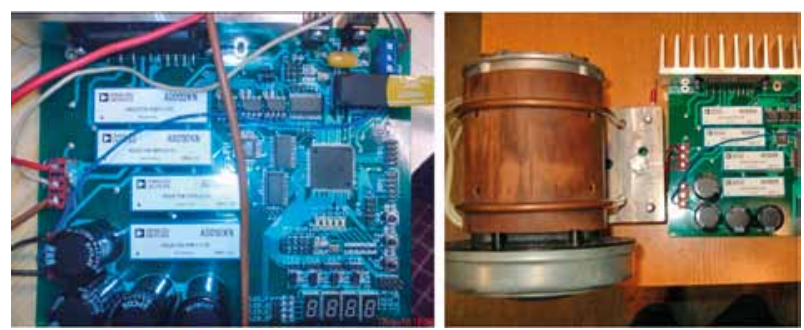

Fig. 3. Photo of the converter and the BLDC motor

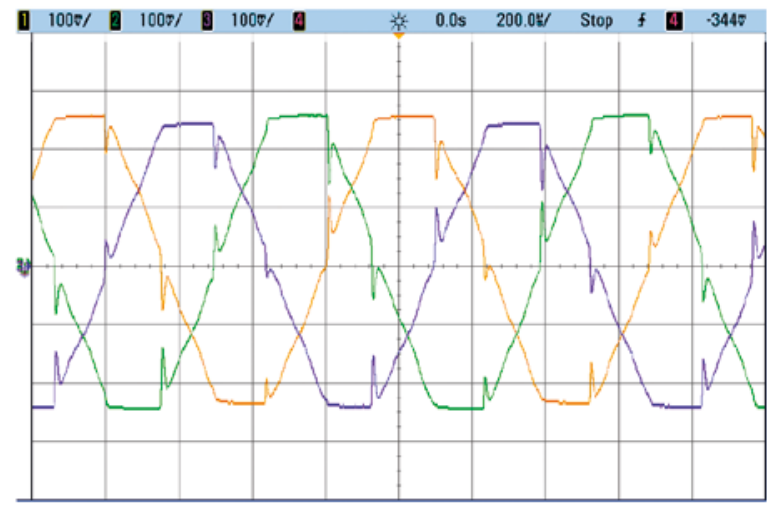

Fig. 4. Output voltage waveforms of the inverter

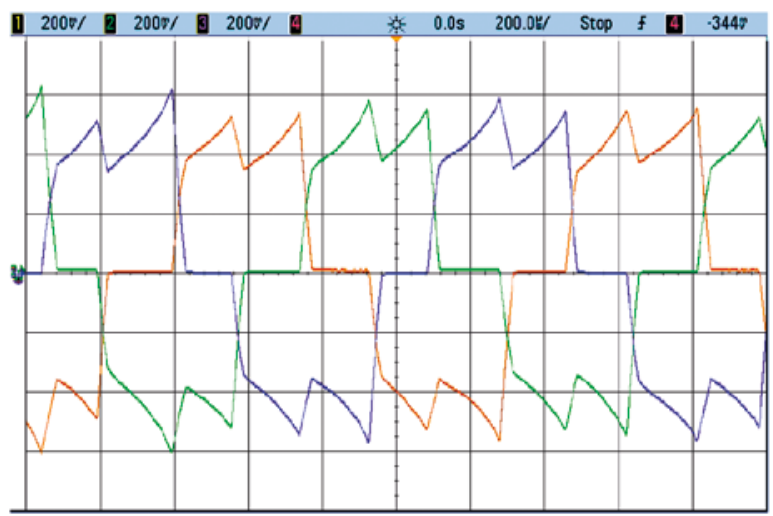

Fig. 5. Phase current waveforms of the BLDC motor
Controllers not only change the battery energy flow, they also protect the motor and batteries from any spikes, shorts, or other anomalies that might occur in the system.

Motor phase currents and voltage waveforms were registered. The output waveforms are given below. Figure 4 shows the output voltage waveforms of the inverter. Figure 5 shows the phase currents of the BLDC motor.

\section{Conclusions}

The electric airplane industry is clearly in its infancy, but developments are happening fast. Its future depends on the cost and energy density of batteries. Flight time is directly proportional to the energy stored, and the energy stored is proportional to the weight of the batteries. Most aircraft to date do not have custom controllers, so a converter and control system was proposed. In the paper, the development, test results and assessment of an advanced cost effective BLDC motor converter for aerospace applications are presented and discussed. The development and certification of any new equipment for aerospace industry requires quality, performance, safety and reliability. Results from this part of investigation can be used as a hardware and software design base. The presented preliminary elaboration will accelerate the BLDC drive design process.

\section{References}

Binkowski, T. 2011. Control of sensorless electrical drive, in $B A L$, SENE, 16-18 November 2011, Łódź, Poland (in Polish).

Binkowski, T.; Buczek, K.; Sobczyński, D. 2011. Control of BLDC motor working as flying hybrid platform component, Przegląd Elektrotechniczny [Electrical Review] 87(8): 30-33. ISSN 0033-2097.

Bo, T.; Ruiqing, M.; Weiguo, L., et al. 2010. Braking technique research on high power permanent magnet brushless motor of aviation, in Advanced Computer Control (ICACC), 2010 2nd International Conference, 27-29 March 2010, Shenyang 3: 467-471. http://dx.doi.org/10.1109/ICACC.2010.5486815

Gapiński, D.; Stefański, K. 2014. Control of designed target seeker, used in self-guided anti-aircraft missiles, by employing motors with a constant torque, Aviation 18(1): 13-19. http://dx.doi.org/10.3846/16487788.2014.865943

Jurecka, R.; Bencalik, K. 2012. Airplanes with an electric motor, Aviation 16(3): 63-68. http://dx.doi.org/10.3846/16487788.2012.732304

Jurković, M.; Žarko, D. 2012. Optimized design of a brushless DC permanent magnet motor for propulsion of an ultra light aircraft, Journal for Control, Measurement, Electronics, Computing and Communications 53(3): 244-254.

Kaddour, M. 2014. Alternative motors in aviation, Aviation 18(4): 174-177. http://dx.doi.org/10.3846/16487788.2014.985472

Luongo, C. A.; Masson, J. P.; Nam, T., et al. 2011. Next generation more-electric aircraft: a potential application for HTS superconductors, IEEE Super Transaction on Applied Superconductivity 19(3): 1055-1068.

http://dx.doi.org/10.1109/TASC.2009.2019021 
Rajashekara, K.; Akin, B. 2013. A review of cryogenic power electronics - status and applications, in Electric Machines \& Drives Conference (IEMDC), 2013 IEEE International, 1215 May 2013 Chicago, IL, 899-904. http://dx.doi.org/10.1109/IEMDC.2013.6556204

Sanita, C. S.; Kuncheria, J. T. 2013. Modelling and simulation of four quadrant operation of three phase brushless DC with hysteresis current controller, International Journal of Advanced Research in Electrical, Electronics and Instrumentation Engineering 2(6): 2461-2470.

Sobczyński, D. 2009. Power electronic converter suplied highspeed small power motors, in BAL, SENE,18-20 November 2009, Łódź, Poland. (in Polish). 